\title{
Environmental preservation based on an inorganic coating
}

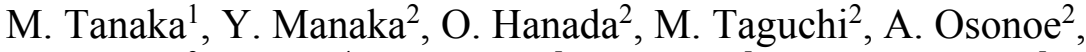

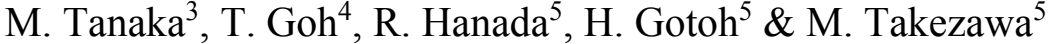 \\ ${ }^{1} N C K-G P$ Pte. Ltd, Singapore \\ ${ }^{2}$ Nihon Chuo Kenkyujo Co. Ltd., Japan \\ ${ }^{3}$ JGC-Trading Co. Ltd., Japan \\ ${ }^{4}$ Sabah Tea SDN. BHD., Malaysia \\ ${ }^{5}$ Nihon University, Japan
}

\begin{abstract}
Recently, abnormal climatic conditions have been reported around the world. The reason for this is presumed to be global warming due to increases in the amount of atmospheric carbon dioxide. In September 2013, the Intergovernmental Panel on Climate Change (IPCC) approved the Fifth Assessment Report in the Summary for Policymakers. The report stated that the global mean surface air temperatures over land and oceans increased over the last 100 years. The Japan Meteorological Agency reported in February 2014 that the global average surface temperature for the year 2013 was estimated at $+0.20^{\circ} \mathrm{C}$ above the 1981-2010 average and ranked as the second warmest on record since 1891, a period of 123 years. Many countries have experienced a wide range of temperatures in recent years. The most comfortable temperature is said to be about $23^{\circ} \mathrm{C}$ with relatively low humidity. This temperature can be achieved in buildings by applying an inorganic coating known by the trade name "Adgreencoat" to walls, roofs, etc., of a variety of buildings, including factories. This inorganic coating can reflect solar radiation and thus control the temperature of a room. This paper describes the control of temperature by using an inorganic coating.

The main conclusions discussed in this paper are as follows: (1) Adgreencoat efficiently reflects solar light and prevents heat accumulation because of its ability to release absorbed heat. This is a coating designed for heat island measures.
\end{abstract}


(2) Adgreencoat can lower the temperature of external air-conditioner units and contribute towards saving energy.

Keywords: inorganic coating, global warning, saving electricity, heat island measure, reduction of load of air-conditioner, reflect and release heat from the sun, radiation heat functionality.

\section{Introduction}

The $36^{\text {th }}$ General Meeting of the Intergovernmental Panel on Climate Change (IPCC) and the $12^{\text {th }}$ Sectional Meeting of Primary Work were held in Stockholm, Sweden in September 2013. At these meetings, the Fifth Assessment Report of the IPCC was approved. The Fifth Assessment Report consists of three Working Group Reports and a Synthesis Report. Working Group I in Stockholm, Sweden reported the Physical Science basis on 30 September 2013, Working Group II in Yokohama, Japan reported the Impacts, Adaptation and Vulnerability on 31 March 2014, Working Group III in Berlin, Germany reported the Mitigation of Climate Change on 11 April 2014, and the Synthesis Report in Copenhagen, in Denmark was reported on 31 October 2014. The outline of the Fifth Assessment Report of the IPCC was developed through a scoping process that involved climate change experts from all relevant disciplines. The Summary for Policy Makers (SPM) states that anthropogenic warming could lead to impacts that are abrupt or irreversible, depending on the rate and magnitude of the climate change. If increases in global average warming exceed $1.5-2.5^{\circ} \mathrm{C}$ (relative to $1980-1999$ ), approximately $20-30 \%$ of species assessed so far are likely to be at increased risk of extinction. If the global average temperature increase exceeds approximately $3.5^{\circ} \mathrm{C}$, model projections suggest significant extinctions $(40-70 \%$ of species assessed) around the globe [1]. The global average temperature increase greatly influences social welfare, such as the welfare of aged and sick people. The health harm due to the temperature increase will induce heat injuries, sleep disorders, food poisoning, infectious diseases, photochemical smog, etc. Rooms with airconditioning will be necessary. However, air-conditioning requires high electricity consumption. The total consumption of primary energy in the world has increased about 3.2-fold in the last 45 years (1965 to 2010). The energy saving for overcoming this situation is very important to maintain amenities for healthy living. This paper describes the control of temperature by using an inorganic coating for constructions/buildings mainly.

\section{Measures of energy saving}

A law about the rationalization of the use of energy was established by the Japanese Government in 1979. The law was intended to contribute to robust development of the national economy through energy saving [2]. The nextgeneration energy-saving standard was established in 1999 [3] for the insulation performance of a whole house and of each outer wall. A design was suggested for the rationalization of energy use by modifying an existing house to improve insulation performance in windows, as well as during house construction. The 
insulation of all new buildings will need to meet the requirements of the standard of the Japanese Government by $2020[4,5]$. The objective of energy saving is the reduction of electric cost and usage of limited energy sources, as well as promoting ecology through the reduction of environmental loads accompanying energy use. The specific methods of energy saving are the improvement of equipment such as air-conditioners and lighting, insulation of buildings, use of fans, greening of walls and roofs, and shielding from thermal energy. In electric energy consumption [6], the electricity pricing varies widely from country to country, and may vary significantly from locality to locality even within a particular country. Energy consumption has been cut on the worldwide level by $1.5 \%$ since 1945 , and each region in the world has reduced energy consumption except Asia and the Middle East. The ecology research pointing to the need for reduction of environmental load implies the need to promote of natural energies such as solar heat, use of natural light, wind power, etc., and the effective utilization of reused raw materials in place of fossil fuels. Some method for obtaining energy saving are as follows: the reduction of energy used in offices by centralized control of air-conditioners, switching lighting from mercury lamps to high ceramic halide lamps, setting up a power monitoring system, and painting an insulation coat on roofs, and conducting energy-saving patrols. Using these methods, the operational cost of an office could be reduced through saving energy.

\section{Comfortable temperatures and humidity}

The World Health Organization declared the definition of health in 1948 as "a state of complete physical, mental, and social well-being and not merely the absence of disease or infirmity" [7]. The International Organization for Standardization established the international standard ISO 1. The ISO 1 standard specifies a standard reference temperature for geometrical product specifications and verification, $20^{\circ} \mathrm{C}$. Due to thermal expansion, precision length measurements need to be made such a reference temperature so that measurements are comparable. The reference temperature of $20^{\circ} \mathrm{C}$ was adopted by the Comit International des Poids et Measures (CIPM) on 15 April 1931, and became ISO recommendation number 1 in 1951 [8]. The Japanese Management Standard of Environmental Sanitation for buildings recommends the temperature of an airconditioned room to be $17-28^{\circ} \mathrm{C}$ and the relative humidity to be $40-70 \%$ [9]. According to the West Midlands Public Health Observatory in the UK, an adequate level of warmth for older people (aged 58 and above) is $23^{\circ} \mathrm{C}$ in the living room, and $24^{\circ} \mathrm{C}$ in other occupied rooms. The maximum comfortable room temperature is $27^{\circ} \mathrm{C}$. Due to variations in humidity and clothing, recommendations for summer and winter may vary; one recommendation for summer is $23^{\circ} \mathrm{C}$ to $26^{\circ} \mathrm{C}$, and one for winter is $24^{\circ} \mathrm{C}$ to $27^{\circ} \mathrm{C}$ [10]. Recently, the American Society of Heating Refrigeration and Air-conditioning Engineers (ASHRAE) established Standard 55, which covers Thermal Environmental Conditions for Human Occupancy, and suggested a new adaptive comfort standard that allows warmer indoor temperatures for naturally ventilated buildings during summer. The outdoor climate environment for each building was characterized in terms of the mean 
outdoor dry bulb temperature, which was used to characterize the optimum comfort temperature was [11]. A thermal index calculated by the wet bulb temperature, black globe temperature, and ambient temperature was invented by Yaglou and Minard in 1957 [12]. Humans and other animals feel heat and humidity, but humans feel pain at high humidity. The heat index (humiture) was developed in 1978 by George Winterling and was adopted by the USA National Weather Service [13].

\section{Thermal barrier of buildings}

The rise of temperatures due to global warming and heat islands will increase the demand for air-conditioners in summer. On one hand, global cooling in winter has been reported in many parts of the world, but also air-conditioners remain in demand. The use of energy is increased by the use of air-conditioners. Thermal barrier reduces heat transfer between objects in thermal contact or within in the range of radiative influence [14]. An inorganic coating known by the trade name "Adgreencoat" can reflect and release the heat from the sun, which functionality stimulates more comfortable room temperature by reducing heat storage [15]. Adgreencoat is easy on the environment because it is an inorganic coating. It was certified by the Environmental Labeling Program in accordance with ISO14020 and ESO14924 (Eco-Mark) of the Law on Promoting Green Purchasing [16]. Adgreencoat, developed by nanotechnology, uses spherical inorganic nonporous ceramics of particle diameter $0.5 \mu \mathrm{m}$, compared to other insulating coats, such as balloon silica with porous ceramics having particle diameters of 20-300 $\mu \mathrm{m}$. Although another functional coat $(\mathrm{G})$ was developed first, which notion is thermal 'insulation', that paint was rough and not as appealing as Adgreencoat, as shown in Fig. 1(a) and (b). The painting film of Adgreencoat after dryness is thin, $100-150 \mu \mathrm{m}$, with a smooth surface; the other coat is $500-1000 \mu \mathrm{m}$ and has a rough surface. Adgreencoat is excellent for construction work because of the thinness and the product delivery is quick. In addition, Adgreencoat is a very attractive coating that does not easily show dirt.

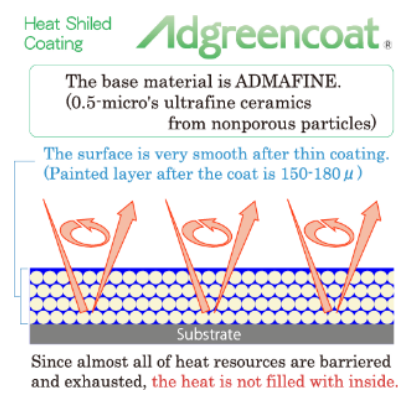

(a) Adgreencoat

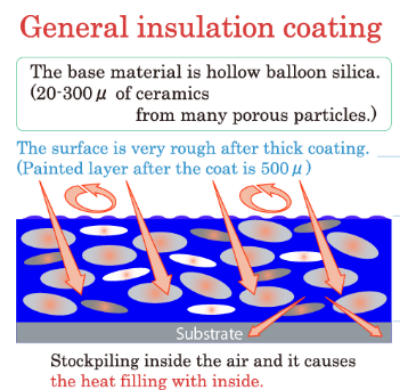

(b) another functional coat $(\mathrm{G})$

Figure 1: Two types of organic coatings. 


\section{Case studies}

\subsection{The house-building factory}

The houses are constructed in a factory, versus being constructed on site. Adgreencoat can contribute to heat shielding at various usages, e.g. different types of buildings. The functional effect for the house-building factory in Okayama Prefecture, Japan was checked by comparison of the roof surface temperatures before and after painting, as shown in Figure 2. The measurement method was a continuous thermo-scope for 24 hours, and the measurement period was from July 2012 to December 2012. The outside air temperature data were from the Meteorological Agency in Japan. In addition, the roof was galvalume steel plate, $27,000 \mathrm{~m}^{2}$ area. The temperatures of the painted part and the unpainted part of the roof were measured when the inside temperature was controlled to $27.5^{\circ} \mathrm{C}$ in August.

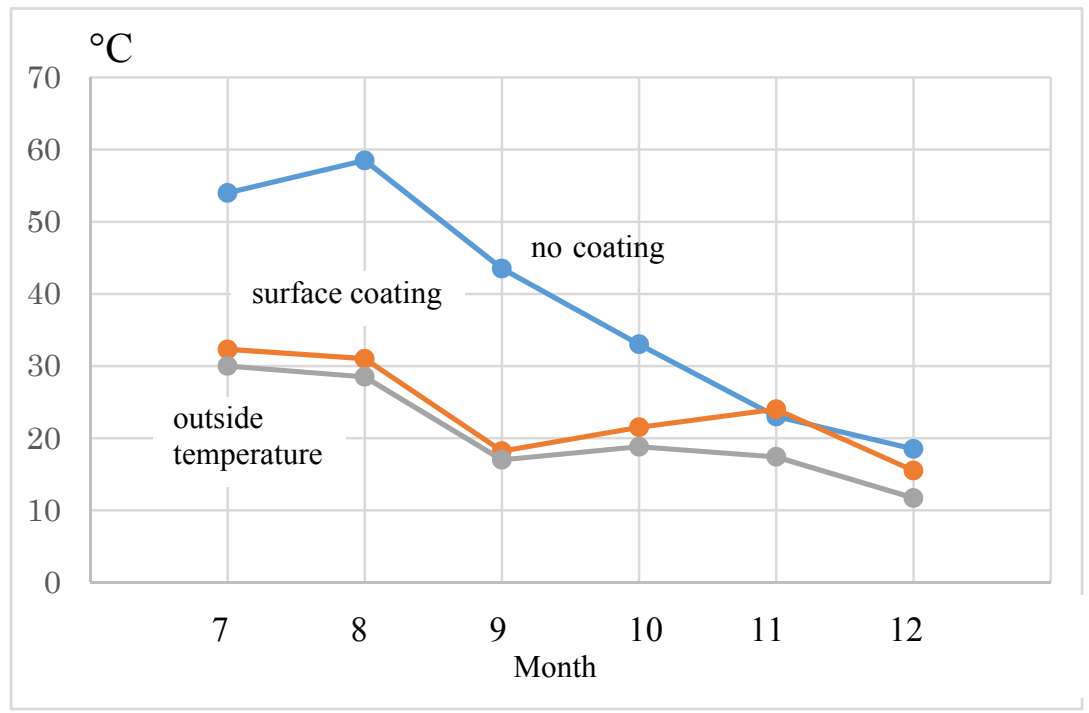

Figure 2: The change of roof surface temperature after applying Adgreencoat.

The room air temperature of the thermal barrier coating part confirmed the temperature lowering effect of about $4^{\circ} \mathrm{C}$ in comparison with the unpainted part in September, as shown in Figure 3. It was demonstrated that Adgreencoat is effective for improving the environment of the workers. Figure 4 is the housebuilding factory. 


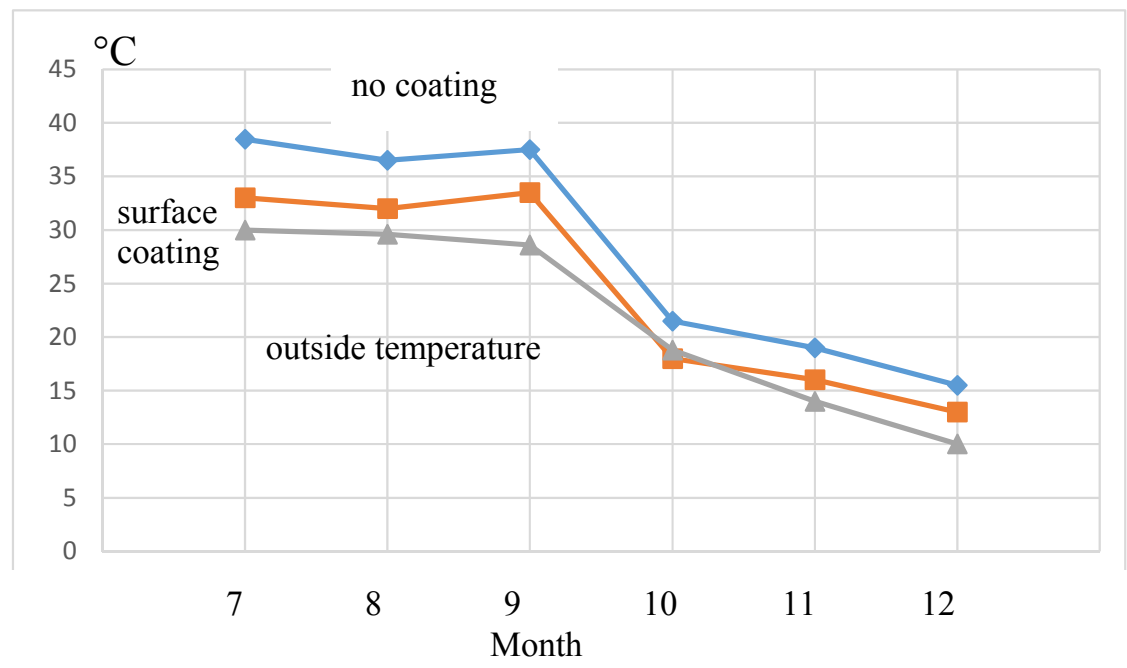

Figure 3: The change of room air temperature.

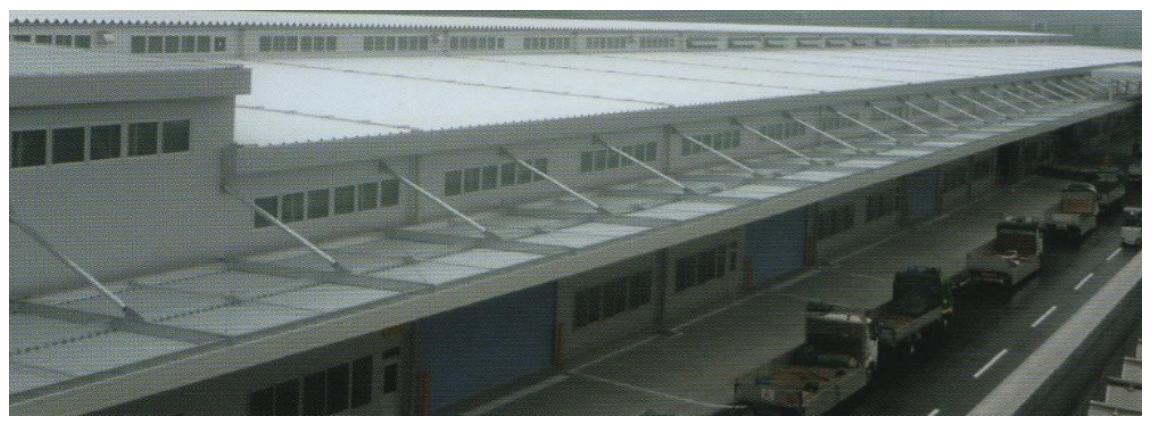

Figure 4: The house-building factory.

\subsection{Warehouse}

A trial implementation of a thermal barrier coated roof was carried out from 18 July 2012 to 9 August 2012. The objective was to analyze the effectiveness of a thermal barrier coated roof on the temperature reduction inside a building, especially in the working area. Figure 5 is the change of temperature at the roof and inside the warehouse. 

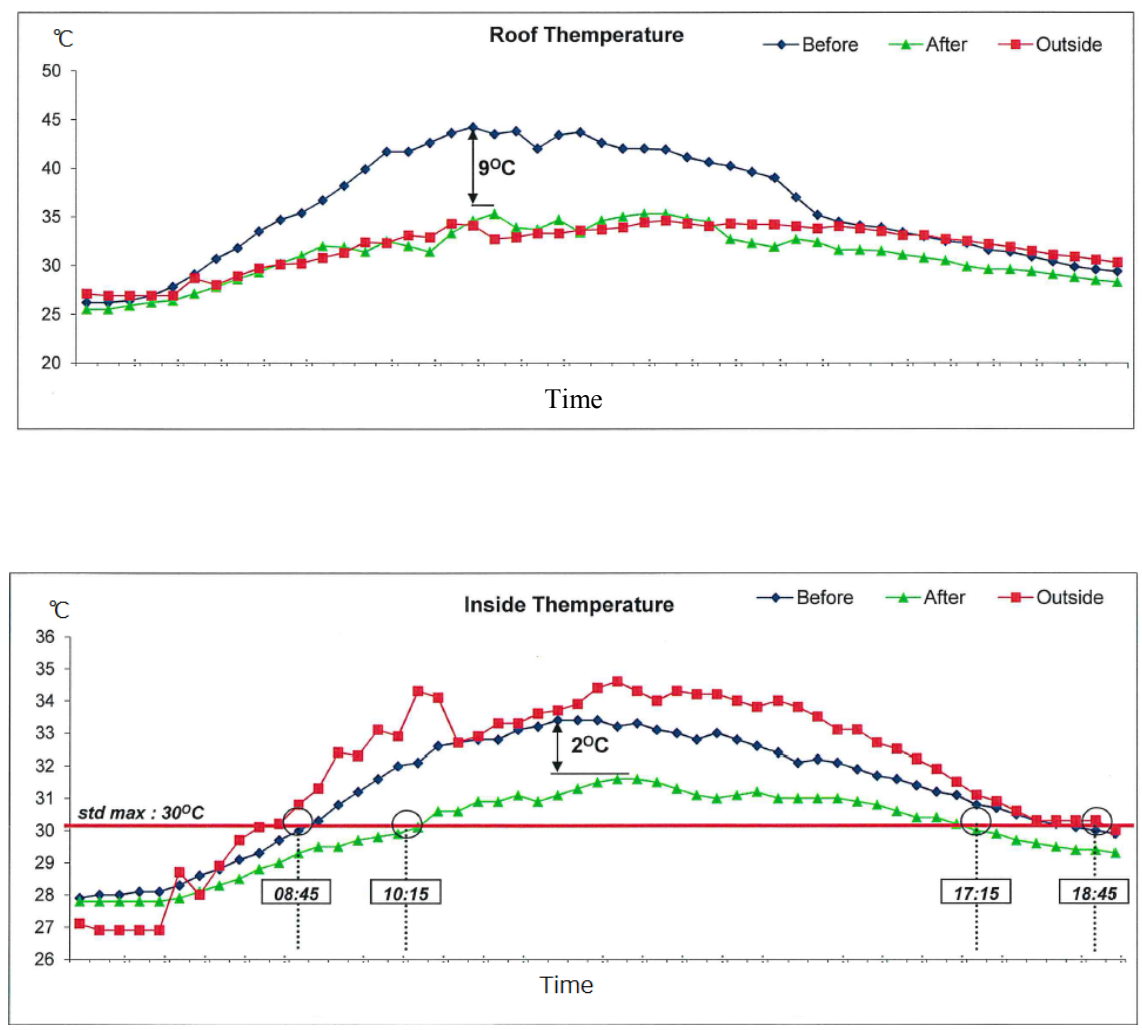

Figure 5: The change of temperature on the roof (top) and inside (bottom).

The average temperature inside was reduced by $2^{\circ} \mathrm{C}$ with the thermal barrier coated roof, but still cannot achieve $30^{\circ} \mathrm{C}$ (standard maximum deviation). However, the duration of daily hot temperatures inside (above $30^{\circ} \mathrm{C}$ ) became smaller, from 10 hours/day to 7 hours/day (i.e. reduced by 3 hours/day).

\section{Electricity usage}

The electricity usage of air-conditioners in a comparison between Adgreencoat, another functional coat $(\mathrm{G})$, and an ordinary white coat was tested in a unit house (area $12.95 \mathrm{~m}^{2}$ and height $2.7 \mathrm{~m}$ ) with glass wool as the roof insulator from 9 August 2010 to 6 September 2010 is shown in Figure 6. As shown, Adgreencoat can reduce by about $20 \%$ the electricity usage in comparison with another functional coat $(\mathrm{G})$ and the ordinary white coat, where the vertical label is electricity usages. Both Adgreencoat and another functional coat $(\mathrm{G})$ colour is grey to compare with an ordinary white coat. 


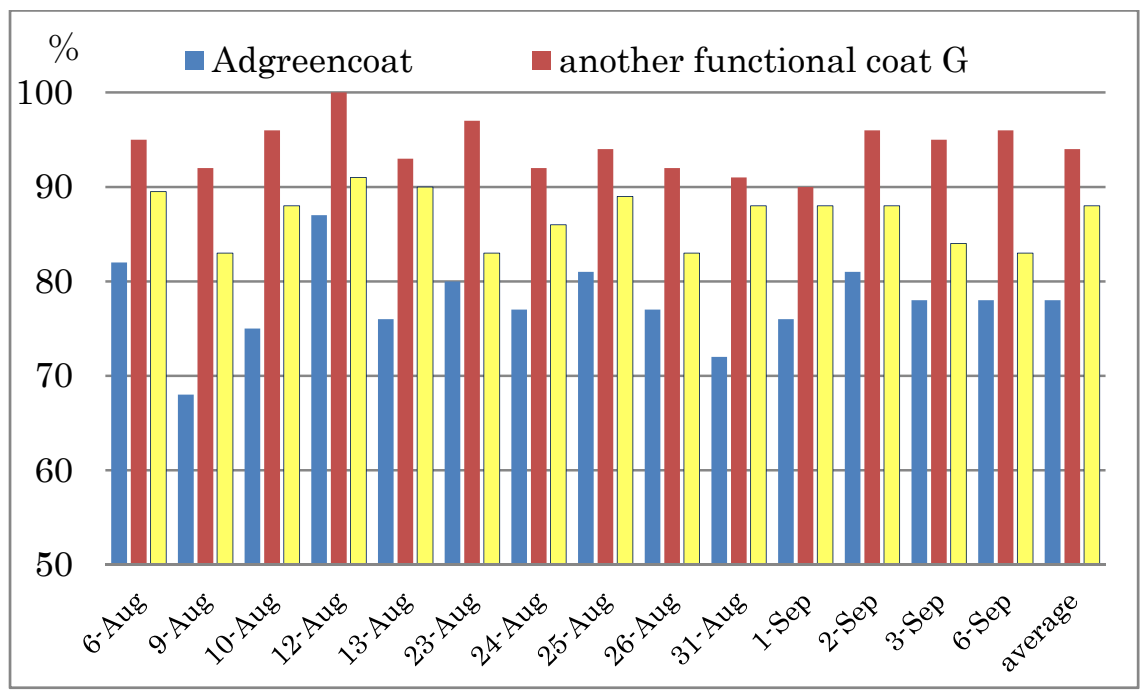

Figure 6: Comparison of Adgreencoat (left), another functional coat G (center), and white coat (right) in a unit house.

An example of a warehouse (area 3,000 $\mathrm{m}^{2}$ ) is shown in Figure 7. The energy saving of $23 \%$ was obtained by using Adgreencoat together with the reduction of lighting and increase of monitoring.

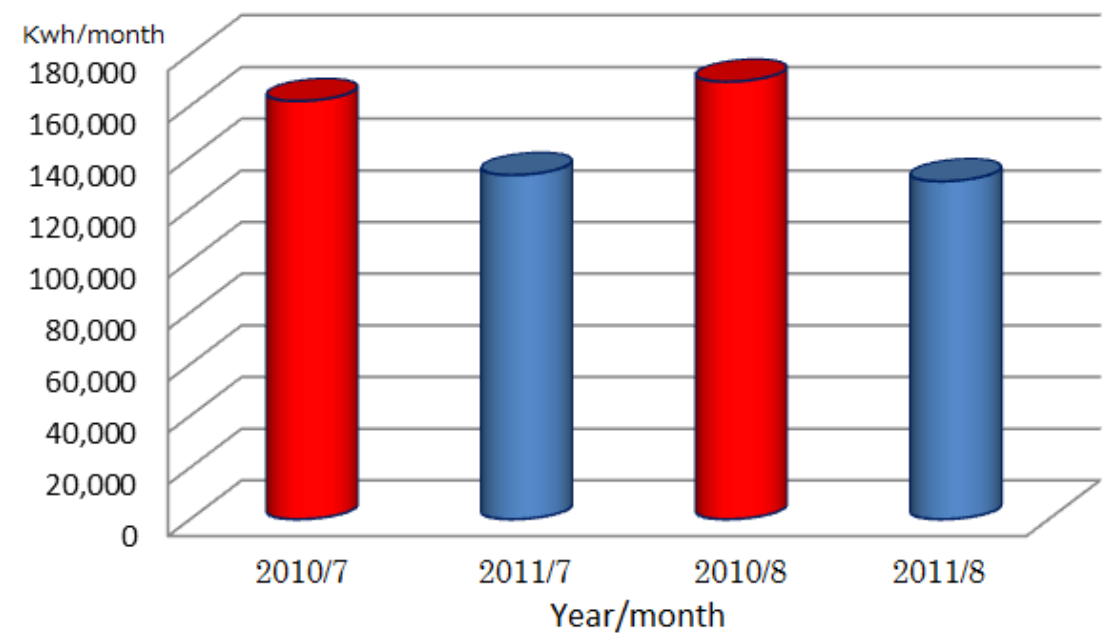

Figure 7: An example of energy saving in a warehouse. 


\section{Conclusions}

We hear frequently that severe heat is forecasted for the future and the roof surface temperatures of office buildings and warehouses will rise to $70-80^{\circ} \mathrm{C}$. Therefore, air-conditioners will be operating at high levels because of the increasing temperatures in the rooms. Adgreencoat will be able to improve such conditions. Adgreencoat can lower the temperature in a room and save electricity because it is able to reflect sunlight and release heat to the outside. Adgreencoat has an inorganic nonporous body containing small grain sizes of ceramics. Adgreencoat has been approved Japan Industrial Standards (JIS) K5675, as its functionality for heat island measure. Also, Adgreencoat is water-based coat, it is eco-friendly and less influence product for health than other solvent-based coats.

The properties of Adgreencoat can be summarized as the following three points: (1) Adgreencoat can reflect light and reduce heat storage, (2) Adgreencoat is attractive due to its non-granular finish, and (3) Adgreencoat is easy to work with and requires little maintenance.

\section{References}

[1] IPCC, Intergovernmental Panel on climate change, ipcc-wg2.gov/AR5/images/uploads/WG2AR5-SPM-FINAL.pdf (accessed 2014/08/30).

[2] ECCJ, Law concerning the Rational Use of Energy, http://www.eccj.or.jp/law/e-law-html (accessed 201408/30).

[3] M. Yokoo, H. Nakagami, C. Murakoshi, Revision of Japanese Housing Energy Efficiency Standards. http://www.eceee.org/library/conferenceproceedings/eceee (accessed 2014/08/31).

[4] T. Sakamoto, Energy Efficiency Policies of Japan, Highlighting Japan. http://www.gov-online.go.jp/pdf/hlj_ar/vol_0021e/22-23.pdf (accessed 2014/08/30).

[5] T. Inoue, New Developments in Building Energy Efficiency Policies of Japan, June 2012, Ministry of Land, Infrastructure, Transport and Tourism in Japan. http://nrw.co.jp/seminare_jp/20120604/Inoue.pdf (accessed 2014/08/30).

[6] Wikipedia, the free encyclopedia, Electric energy consumption. http://en.wikipedia.org/wiki/Electric_energy_consumption (accessed 2014/08/09).

[7] WHO Association of Japan, The WHO Charter, http://www,japanwho.or.jp/commodity/kensyo.html (accessed 2014/08/11).

[8] Wikipedia, the free encyclopedia, Thermal comfort. http://en.wikipedia.org/wiki/Thermal_comfort (accessed 2014/08/18).

[9] Ministry of Health, Labor and Welfare, The Management Standard of Environmental Sanitation for Buildings. http://www.mhlw.go.jp/bunya/kennkou/seikatsu-eisei10/index.html (accessed 2014/08/31).

[10] Wikipedia, the free encyclopaedia, Room temperature. 
http://www.en.wikipedia.org/wiki/Ambient_temperature (accessed 2014/ 08/17).

[11] ASHRAE, Thermal Environmental Conditions for Human Occupancy. http://www.ashrae.org/resources--publications/bookstore/standard-55 (accessed 2014/08/31).

[12] C. P. Yaglou, and D. Minard, (1957) Control of Heat Casualties at Military Training Centers, Archives of Industrial Health, 16.

[13] Wikipedia, the free encyclopaedia, Heat index. http://en.wikipedia.org/wiki/Heat_index (accessed 2014/08/18).

[14] Wikipedia, the free encyclopaedia, Thermal insulation. http://en.wikipedia.org/wiki/Thermal_insulation (accessed 2014/08/19).

[15] O. Hanada, et al., (2010) Study on Inorganic Coat, International Conference of Heat Transfer, WIT Press (UK).

[16] NCK, The Energy Saving Eco Coating, http://eps4.comlink.ne.jp/office21/adgreen-3.html (accessed 2014/08/31). 